\title{
Effect of stress on NiO reduction in solid oxide fuel cells: A new application of energy- resolved neutron imaging
}

Makowska, Malgorzata; Strobl, Markus; Lauridsen, Erik Mejdal; Frandsen, Henrik Lund; Tremsin, Anton S.; Kardjilov, Nikolay; Manke, Ingo; Kelleher, Joe F.; Kuhn, Luise Theil

Published in:

Journal of Applied Crystallography

Link to article, DOI:

$10.1107 / S 1600576715002794$

Publication date:

2015

Document Version

Peer reviewed version

Link back to DTU Orbit

Citation (APA):

Makowska, M., Strobl, M., Lauridsen, E. M., Frandsen, H. L., Tremsin, A. S., Kardjilov, N., Manke, I., Kelleher, J. F., \& Kuhn, L. T. (2015). Effect of stress on NiO reduction in solid oxide fuel cells: A new application of energyresolved neutron imaging. Journal of Applied Crystallography, 48, 401-408. https://doi.org/10.1107/S1600576715002794

\section{General rights}

Copyright and moral rights for the publications made accessible in the public portal are retained by the authors and/or other copyright owners and it is a condition of accessing publications that users recognise and abide by the legal requirements associated with these rights.

- Users may download and print one copy of any publication from the public portal for the purpose of private study or research.

- You may not further distribute the material or use it for any profit-making activity or commercial gain

- You may freely distribute the URL identifying the publication in the public portal 


\section{Effect of stress on $\mathrm{NiO}$ reduction in solid oxide fuel cells - a new application of energy-resolved neutron imaging}

Authors

Malgorzata G. Makowska $^{\text {ab*, Markus Strobl }}{ }^{\mathrm{b}}$, Erik M. Lauridsen ${ }^{\mathrm{c}}$, Henrik L. Frandsen ${ }^{\mathrm{a}}$, Anton

S. Tremsin ${ }^{\mathrm{d}}$, Nikolay Karjilov ${ }^{\mathrm{e}}$, Ingo Manke ${ }^{\mathrm{e}}$, Joe F. Kelleher ${ }^{\mathrm{f}}$ and Luise T. Kuhn ${ }^{\mathrm{a}}$

a Department of Energy Conversion and Storage, Technical University of Denmark, Frederiksborgvej 399, Roskilde, 4000, Denmark

${ }^{\mathrm{b}}$ European Spallation Source ESS AB, P.O Box 176, Lund, SE-221 00, Sweden

'Xnovo Technology ApS, Galoche Alle 15, Køge, 4600, Denmark

${ }^{\mathrm{d} S p a c e}$ Sciences Laboratory, University of California at Berkeley, Berkeley, CA 94720, USA

${ }^{\mathrm{e}}$ Helmholtz-Zentrum Berlin für Materialien und Energie GmbH, Berlin, D-14109, Germany

fISIS Facility, Rutherford Appleton Laboratory, Chilton, OX11 0QX, UK

Correspondence email: malg@dtu.dk

Synopsis In this work the authors demonstrate the great potential of energy-resolved neutron imaging for studies of two important phenomena taking place in SOFC anode supports: accelerated creep and reduction nucleation due to applied stress.

Abstract Recently, two new phenomena linking stress field and reduction rates in anode-supported Solid Oxide Fuel Cells (SOFCs) have been demonstrated, so-called accelerated creep during reduction and reduction rate enhancement and nucleation due to stress(Frandsen et al., 2014). These complex phenomena are difficult to study and we demonstrate here that energy resolved neutron imaging is a feasible technique for combined mechanics-chemical composition studies of SOFC components, including commercially produced ones. Cermet (Ni-YSZ) anode supports, which prior to the measurements were reduced under varying conditions such as different temperatures, varying times and under different values of applied stress, have been measured. Thus, samples with different contents (and gradients) of $\mathrm{Ni}$ and $\mathrm{NiO}$ phases were investigated. The first Bragg edge transmission neutron measurements applied for the studies of reduction progress in samples were performed at two neutron beamline facilities (ISIS in UK, HZB in Germany). Obtained results demonstrate the possibility to image and distinguish $\mathrm{NiO}$ and $\mathrm{Ni}$ phases within SOFC anode supports by energy resolved neutron imaging and the potential of neutron imaging method for in situ studies of reduction processes.

\section{Introduction}


Solid oxide fuel cells (SOFCs) offer a promising green technology of direct conversion of chemical energy of fuel into electricity. This technology is close to commercialization, but still a great effort has to be made to optimize the performance, durability and mechanical integrity of fuel cellls, which currently are among the largest market entry barriers of SOFC (Christiansen et al., 2013).

An SOFC is composed of at least three layers with thicknesses in the sub millimeter range; a porous anode, a gas tight electrolyte and a porous cathode (Singhal, 2000; Stambouli \& Traversa, 2002; Malzbender et al., 2009) . Many of the commercial cells include an additional layer, which acts as a mechanical support on the anode side, the so-called anode support (Christiansen et al., 2013). They are made of brittle ceramic components and when stacked and under operation conditions they are continuously exposed to stress from temperature gradients and external loads. These stresses might cause failures. Therefore, understanding the microstructure and stress distribution and changes during production and operation in particular layers is crucial for the integrity and thus the commercialization of the SOFC technology (Malzbender et al., 2005).

In this work the authors demonstrate the great potential of energy-resolved neutron imaging for studies of phenomena related to both reduction reaction and stress, which take place in commercial SOFC anode supports. The state of the art material for anodes and anode supports is a cermet composed of $\mathrm{Ni}$ and YSZ (yttria $\left(\mathrm{Y}_{2} \mathrm{O}_{3}\right)$ stabilized zirconia $\left(\mathrm{ZrO}_{2}\right)$ ). The content of yttria varies between $3 \mathrm{~mol} \%$, which due to its high strength and toughness (Ghatee et al., 2009) is usually used for anode supports, and $8 \mathrm{~mol} \%$, which is used for anodes. Commercial anode support layers are often produced using tapecasting of an NiO-YSZ slurry. During the initial operation of the cell, $\mathrm{NiO}$ particles are reduced to metallic Ni (Klemensø et al., 2006) that will then act as an electrocatalyst in the operating cell. The porosity of anode supports and anodes required for fuel transport is obtained during this $\mathrm{NiO}$ reduction as well. Thus, the conditions in which this process is occurring determine the microstructure of the anode and anode support and significantly influence the mechanical and electrochemical properties of the fuel cell (Klemensø et al., 2006; Wang et al., 2006; Li et al., 2010; Moseley et al., 2011).

Recently, Frandsen at al. have discovered two new phenomena in SOFC anode supports (Frandsen et al., 2014). The first phenomenon was the tremendous deformation of the SOFC anode supports occurring at high temperature due to simultaneous exposure to reducing atmosphere and stress. The observed deformation was a few orders of magnitude bigger than deformation occurring at elevated temperature during exposure only to one of these factors (stress or reducing atmosphere). This effect is later called "accelerated creep". The second new phenomenon was the reduction rate enhancement due to the applied external stress (Frandsen et al., 2014). These phenomena notably change the stress field in an SOFC stack (Sun et al., 2009; Frandsen et al., 2014) and influence the microstructure of the anode supports. In this work we demonstrate how energy-resolved neutron imaging can be applied to study these phenomena in greater detail. Observation of $\mathrm{NiO}$ reduction in pure solid $\mathrm{NiO}$ was studied with neutron Bragg edge transmission already by S. Vogel (Vogel et al., 2002). Here, however, the 
first energy-resolved neutron imaging measurements, i.e. with spatial resolution, of $\mathrm{NiO}$ reduction in the porous composite material for commercial SOFC anode supports are presented. This is not only a novel application of this technique, but has, as it is shown here, the potential for systematic studies of this crucial process with respect to different reduction conditions such as temperature, external stresses and atmosphere, as they might occur in operating SOFCs . In particular, this work is the first evidence of the feasibility of applying energy-resolved neutron imaging for observing and distinguishing of $\mathrm{NiO}$ and $\mathrm{Ni}$ phases within commercial SOFC anode supports with spatial resolution.

\section{Experimental}

\subsection{Sample preparation}

The influence of mechanical loading on the reduction reaction progress of $\mathrm{NiO}$ in material used for anode supports in commercial SOFCs, i.e. NiO mixed with 3 mol\% YSZ (3YSZ) has been investigated. Typical thicknesses of anode supports for solid oxide fuel cells are in the range between $300 \mu \mathrm{m}$ and $1 \mathrm{~mm}$ (Hecht et al., 2005; Patel et al., 2012) and layers of different thicknesses within this range were studied. Standard anode supports of SOFC produced at Technical University of Denmark (DTU) are $300 \mu \mathrm{m}$ thick and are produced using tape-casting. A detailed description of this fabrication procedure can be found elsewhere (Ramousse et al., 2007). Layers thicker than $300 \mu \mathrm{m}$ were obtained by stacking and hot pressing ( $200 \mathrm{kN}$ applied for $1 \mathrm{~min}$ ) of several layers (4-5) of the DTU standard anode support tape. After hot pressing at $130^{\circ} \mathrm{C}$, layers were sintered. This process was conducted in the following steps: heating with rate $15^{\circ} \mathrm{C} / \mathrm{h}$ for $4 \mathrm{~h}$ at $600^{\circ} \mathrm{C}$, heating with rate $60^{\circ} \mathrm{C} / \mathrm{h}$ for $12 \mathrm{~h}$ at $1315^{\circ} \mathrm{C}$, and then cooling with rate $60^{\circ} \mathrm{C} / \mathrm{h}$ to room temperature.

The anode supports were reduced in an atmosphere of $9 \% \mathrm{H}_{2}$ and $91 \% \mathrm{~N}_{2}$ at different temperatures (in the range $600^{\circ} \mathrm{C}-800^{\circ} \mathrm{C}$ ). Each sample was heated in air, and the reduction atmosphere was applied at the desired temperature. During heating, reduction and cool-down, external stress was applied to the sample (by applying constant force) and deformation of the sample due to the external load was observed in-situ using a camera placed in front of the window in the furnace (fig 1b).

In the first phase of this research a series of experiments has been conducted with samples held at different temperatures with external stress applied, after which the samples were totally reduced. The initial elastic bending was small, and significant bending of the samples (fig. 2) was observed only after applying the reducing gas atmosphere in the furnace. This indicates that accelerated creep only occurs during the reduction of $\mathrm{NiO}$ (Frandsen et al., 2014). Thus, an approximated time for the reduction process could be derived from the duration of the observed bending process. A strong dependence of the reduction progress on the temperature was observed, and according to these results, it was possible to roughly estimate the time needed for a certain degree of partial reduction of the anode supports at different temperatures. 
In the next phase the dependence of the reduction rate on the external stress was studied. A set of samples with possible differences in reduction rates on opposite sides of the sample due to different stress fields (compression or tension) induced on either side were prepared. These samples were reduced at three different temperatures $\left(650^{\circ} \mathrm{C}, 700^{\circ} \mathrm{C}\right.$ and $\left.800^{\circ} \mathrm{C}\right)$ and with different amount of stress applied using the fixture shown in fig. 1a. The reduction processes were interrupted at different stages and samples with different reduction rates, i.e. different content of $\mathrm{Ni}$ and $\mathrm{NiO}$ phases, were obtained. This was achieved by fast cool-down of the samples by not only cooling the whole furnace $\left(300^{\circ} \mathrm{C} / \mathrm{h}\right)$, but also moving the samples within a few seconds to a region in the furnace with much lower temperature $\left(300^{\circ} \mathrm{C}, 350^{\circ} \mathrm{C}\right.$ and $450^{\circ} \mathrm{C}$, respectively) while switching the atmosphere to pure nitrogen. Details of the specific preparation processes are provided in table 1.

\subsection{Energy-resolved neutron transmission measurements}

Energy resolved neutron imaging, i.e. transmission studies with spatial and wavelength resolution, do in principle allow the investigation of different reduction rates within a sample, due to crystalline phase dependent elastic scattering from the sample. When neutrons pass through a polycrystalline material, coherent elastic scattering of neutrons takes place and decreases the intensity of the transmitted beam (Fermi et al., 1947). For a specific crystal lattice spacing $d_{h k l}$ such Bragg scattering depends on the orientation of crystallites to the incident beam and the neutron wavelength $\lambda$, according to Bragg's law:

$n \lambda=2 d_{h k l} \sin \theta$

As long as the angle $\theta$ between the incoming beam and the corresponding specific crystal lattice planes (hkl) is less than or equal to $\frac{\pi}{2}$ Bragg scattering can take place at a certain wavelength. In fact, for $\theta=\frac{\pi}{2}$, the sine becomes equal to 1 , and $\lambda=2 d$. At wavelengths longer than that consequently no such scattering at the corresponding lattice planes can take place anymore and the attenuation coefficient drops dramatically. These features in the wavelength dependent attenuation spectra are referred to as Bragg edges, which thus provide measures of the lattice spacings $d_{h k l}$, that are present in a sample. Similar to diffraction peaks measured at corresponding scattering angles, the specific transmission signal of Bragg edges can be used to achieve various crystallographic information e.g. crystal structure, crystalline phases present in a sample or distortions of the lattice plains due to strain (Vogel, 2000; Santisteban et al., 2001, 2002; Iwase et al., 2009; Josic et al., 2011; Lehmann et al., 2011; Woracek et al., 2011, 2014; Kardjilov et al., 2012; Tremsin et al., 2012a). Since this technique is based on measurements of transmitted radiation, experiments can be performed in an imaging geometry and hence provide a means to correlate the measured crystalline properties with spatial information (Santisteban et al., 2001, 2002; Iwase et al., 2009; Josic et al., 2011; Lehmann et al., 2011; Woracek et al., 2011; Kardjilov et al., 2012; Tremsin et al., 2012a). 
The principle of the Bragg edge transmission and imaging techniques are provided in more detail in (Vogel, 2000; Santisteban et al., 2001, 2002; Iwase et al., 2009; Josic et al., 2011; Lehmann et al., 2011; Woracek et al., 2011; Kardjilov et al., 2012; Tremsin et al., 2012a). A precondition for such measurements is however to be able to achieve suitable neutron energy, i.e. wavelength, resolution. At continuous neutron sources this can be obtained by utilization of either monochromators (Treimer et al., 2006), energy selectors (Santisteban et al., 2001; Lehmann et al., 2011) or choppers (Strobl et al., 2011, 2012). Although also in the latter case a time-of-flight (TOF) approach (Vogel, 2000; Santisteban et al., 2001, 2002; Iwase et al., 2009; Tremsin et al., 2012a) is applied, this specific technique is most efficiently applied at pulsed neutron sources, where the initial neutron pulses are short and the significant distance from the source $(15-50 \mathrm{~m})$ enable high wavelength resolution (Strobl, 2009). For this study, measurements have been conducted using both a monochromator setup at the reactor neutron source (continuous source) of the Helmholtz Zentrum Berlin (HZB) and the TOF method at the pulsed spallation neutron source of the Rutherford Appleton Laboratory (ISIS) (Zhang et al., 2013).

At ISIS (Zhang et al., 2013), TOF transmission measurements were performed at ENGIN-X, an engineering diffractometer that can be equipped with a TOF imaging detector. The transmitted beam intensity was measured using a micro-channel plate (MCP) detector with a pixel size of $55 \mu \mathrm{m}$ (Tremsin et al., 2012a; b, 2013). At a pulsed spallation neutron source, a polychromatic neutron pulse is produced by the source and neutrons with different energies / velocities reach the detector after different flight times. The flight path (L) at ENGIN-X was fixed to $50 \mathrm{~m}$, and the wavelengths of neutrons could therefore be calculated from:

$\lambda=\frac{h}{m} \frac{T O F}{L}$,

where $\mathrm{h}$ is the Planck constant, and $\mathrm{m}$ is the neutron mass. The samples were placed as close to the detector as possible $(1 \mathrm{~cm})$, in order to achieve the best possible spatial resolution (approximately 180 micrometer). The field of view was $2.8 \mathrm{~cm}$ diameter circle, which was sufficient to measure several samples at once. In order to normalize the images, the open beam intensity was measured as well. The wavelength resolution of this approach is given by the burst time of the source pulse and the TOF, which is dependent on the instrument length $\mathrm{L}$ and the wavelength. The usable wavelength range is given by the source frequency, if no pulses are suppressed by additional choppers. For the presented measurements a two-fold pulse suppression mode was utilized, providing a spectrum from $1.4 \AA$ to $6.0 \AA$. The wavelength resolution was around $0.04 \%$ (depending on the wavelength), which is significantly better than required. Thus, the recorded data were binned, leading to sufficiently smooth spectra. 
In addition to SOFC supports, at ENGIN-X reference pellets of pure $3 \mathrm{YSZ}$ were measured in order to define the positions of the Bragg edges of 3 YSZ and their respective relation to, i.e. potential overlap with $\mathrm{Ni}$ and $\mathrm{NiO}$ edges.

Further neutron imaging measurements were conducted at the reactor neutron source of the Helmholtz Zentrum Berlin using the CONRAD instrument (Kardjilov et al., 2011). Energy resolved transmission measurements were performed in the wavelength range $4.00 \AA-4.30 \AA$ in steps of $0.01 \AA$ with a wavelength resolution of $3 \%$. The monochromatic beam was achieved with a double-crystal monochromator (Treimer et al., 2006). The total time of exposure for each step was $10 \mathrm{~min}$, but for better quality of normalization of the data five radiographs were measured, each for 2 min for each wavelength. The whole experimental procedure was repeated without samples in order to measure the open beam intensity, which was necessary for the normalization of the images. Normalized data was calculated from eq. 3 , where both - open beam intensity $I_{O B}$ and dark field images $I_{D F}$, measuring the background noise with closed experiment shutter, are taken into account. In this case, a constant average value of dark field $I_{D F}$, which is dominated by the readout noise of the camera system was subtracted.

$I_{n}=\frac{I-I_{D F}}{I_{O B}-I_{D F}}$

As a detector, a standard setup consisting of a ${ }^{6} \mathrm{LiF}$ scintillator and CCD camera with $30 \mu \mathrm{m}$ pixel size (Williams et al., 2012) was used, providing an intrinsic spatial resolution of about $60 \mu \mathrm{m}$.

\subsection{Scanning electron microscopy}

The microstructure and the composition of the samples was investigated for selected samples by a scanning electron microscope (SEM) Zeiss SUPRA 35 equipped with a field emission gun and an Noran energy dispersive X-ray spectroscopy system and operated at $15 \mathrm{kV}$. Cross sections of the samples were embedded in epoxy resin, polished and covered with a nanometer thin carbon layer. The standardless EDS analysis was performed using the Thermo Scientific NSSsoftware to determine the chemical composition.

Figure 3 shows SEM micrographs acquired with the back-scattered electrons (BSE) detector of the cross section of the sample B measured for an area close to the surface (a) and an area in the center (b). As seen in the SEM images significant differences in microstructure and phases can be observed between the center and the surface of sample B. The differences in contrast indicate the presence of different phases (3YSZ, NiO and $\mathrm{Ni}$ ) in both samples. Decrease of pore and particle sizes near the surface Fig. 3(a) (compared to the center of the sample Fig. 3 (b)) is apparent as well (Klemensø et al., 2006).

\section{Results and discussion}


This work presents the first energy resolved neutron transmission imaging studies of $\mathrm{NiO}$ reduction in the porous composite material for commercial SOFC anode supports, which are in good agreement with theoretical data presented in (Allen et al., 1954). Table 2 provides the set of samples analyzed at the two different neutron imaging instruments (names of the samples correspond to terminology used in table 1).

\subsection{Measurements at ENGIN-X}

Fig.4 shows the macroscopic neutron scattering cross-section (linear attenuation coefficient) measured at ISIS at ENGIN-X for samples A and B. Sample A was in the non-reduced state (containing two phases: $\mathrm{NiO}$ and 3YSZ), and the corresponding pattern (green line) exhibits the Bragg edges characteristic for $\mathrm{NiO}$ and 3YSZ. Data were smoothed using a 'moving average' with a span of 20 data points (taken with $20 \mu$ s timing resolution) leading to sufficiently smooth spectra while still maintaining the required wavelength resolution. The stage of phase transition in sample B was not known before the neutron measurements. The sample was exposed to reducing conditions without external stress, and was subsequently cooled down in an oxidizing atmosphere (air flow with atmospheric pressure) in contrast to other samples, which were cooled in nitrogen. After this treatment the sample surface displayed green coloration, which indicated the presence of $\mathrm{NiO}(\mathrm{Ni}$ shows grey coloration). However, the corresponding pattern (average for the whole sample volume) very clearly shows the edges characteristic for $\mathrm{Ni}$, and only a small indication from a $\mathrm{NiO}$ phase is visible. The decrease in the neutron cross section around $3.65 \AA$ present in both patterns corresponds to the $3 \mathrm{YSZ}$ phase.

The beam attenuation from different areas, i.e. slices, of sample B to investigate the degree of reduction across the sample was compared. Fig. 5 presents the patterns for different positions in the sample: slices of thickness $200 \mu \mathrm{m}$ near to the surface and in the center. Visible discontinuities in the spectra are caused by the gaps in the acquisition, which were required for the optimization of the detector performance (Tremsin et al., 2014). It is clear that in the volume close to the surface (green line) both $\mathrm{NiO}$ phase (the edges $\mathrm{NiO}(220)$ at $2.95 \AA, \mathrm{NiO}(200)$ at $4.17 \AA$ are visible) and Ni phase (the edges characteristic for $\mathrm{Ni}$ are visible as well) are present, while inside the sample only Ni phase was observed. Such analysis shows that the sample was fully reduced to Ni (inside only the Ni phase is apparent), and later re-oxidized at a thin surface layer, which apparently took place during cooling down in air.

The results achieved at ENGIN-X at ISIS clearly indicate the feasibility of the method for detecting and distinguishing of $\mathrm{Ni}$ and $\mathrm{NiO}$ phases in SOFC anode supports with spatial image resolution, which has been later confirmed by EDS measurements at selected positions. The average amount of $\mathrm{Ni}$ in both areas was found by EDS to be constant, but the content of oxygen close to the surface was found to be significantly higher at the surface than in the center of the sample. Average mass 
percentage of oxygen near the surface calculated for the area shown in the microscopy image presented in fig. 3a was $24 \%$. In the center of the sample (fig. $3 b$ ) the mass percentage of oxygen was $11 \%$. Thus, darker areas in figure $3 \mathrm{a}$ were identified as the $\mathrm{NiO}$ particles, and the brighter particles are composed of 3 YSZ. Also decrease of pore sizes near the surface (3a) (in comparison to the center of the sample) indicates re-oxidation of Ni particles in this area (Klemensø et al., 2006). We have also conducted a series of SEM investigations of cross sections of a sample before reduction and no variations in the microstructure were observed across the sample width. This supports the hypothesis that differences in porosity in the sample B occurred only during later treatment, and not during sample production. The Bragg-edge analysis is in contrast to the EDS analysis, non-destructive and averaging over a larger sample volume, and hence holds the potential of being applied in-situ. Such in-situ studies are already in progress as a follow-up to the research presented in this paper.

\subsection{Measurements at CONRAD}

Further studies were conducted at CONRAD at HZB utilizing a continuous source. In this case, Bragg edges were measured by scanning the wavelength using a double-crystal monochromator (Treimer et al., 2006), meaning that an image at one particular wavelength is measured at any one time. It is therefore reasonable to limit the wavelength range to the minimum required (also considering the measurement times such approach implies at a medium flux source). According to the initial results and theoretical data (Allen et al., 1954) the probed wavelength range was therefore limited to $4.00 \AA$ $4.30 \AA$. This range includes the most distinct Bragg edges for both $\mathrm{NiO}((200)$ at $4.17 \AA)$ and $\mathrm{Ni}$ ((111) at $4.06 \AA$ ), which also do not overlap with any of the 3 YSZ edges.

Using this setup, anode supports in three different reduction stages have been measured: not reduced, completely reduced (without external load) and one, which was only partly reduced under applied external load (using the setup presented in fig. 1 with a load weight $2,2 \mathrm{~N}$ ).

Figure 6 presents Bragg edges measured at CONRAD for three anode supports at these different stages of processing: a) before reduction (sample A, containing only NiO and $3 \mathrm{YSZ}$ phases), b) after reduction (sample $\mathrm{C}$-only $\mathrm{Ni}$ and $3 \mathrm{YSZ}$ phases) and c) partially reduced (sample $\mathrm{D}$, containing $\mathrm{NiO}$, $\mathrm{Ni}$ and 3 YSZ phases). The wavelength resolution ( $\mathrm{d} \lambda / \lambda$ ca. 3\%) achievable at CONRAD does not allow to fully resolve , i.e. clearly separate, edges, which are as close to each other as $\mathrm{Ni}$ (111) (4.06 $\AA$ ) and $\mathrm{NiO}(200)(4.17 \AA)$. The obtained curves are corresponding superpositions of these two edges. Therefore, the phase transition can be determined by the change of the slope of the measured edge. The plots made for different regions (slices) for samples A and $\mathrm{C}$ show the characteristic edges for $\mathrm{NiO}$ (200) and Ni (111), respectively, and they don't exhibit significant differences within the different slices. Shift of the curve up or down without a slope change can be a result of differences in alignment of the samples (e.g. due to limited spatial resolution it can be difficult to define the edge of sample on the radiograph, the limited spatial resolution leads to limited alignment of the sample edge 
parallel to the beam as well as to overlap of attenuated and open beams on the detector in such area). However, these problems will only shift the curve up or down but not affect the position or the slope of the edge.

The plots in figure 6a show the Bragg edges for the compressed side, the centre area and the tensioned side of the sample C (partially reduced under external stress). Differences in the Bragg edges for these three regions are apparent and it is clear that on the compressed side, higher amounts of Ni phase are present than on the tensioned side. The difference between the two sides of the sample is more evident in Fig. 7, which presents the plots of first derivatives with respect to wavelength of the macroscopic cross sections of a) compressed side and b) tensioned side of sample D (red lines) with reference curves: for reduced sample (blue line) and nonreduced sample (green line).

These results indicate a correlation between compressive stresses applied to the anode supports and the early stage reduction rate in the material under conditions (temperature and atmosphere) similar to during SOFC operation. In particular, the observation of a higher content of the reduced Ni phase on the compressed side of the sample can indicate that external compression stress applied to the material can accelerate the reduction reaction. No such asymmetry in amount of reduced phase was observed in the reoxidized sample B, which was produced without applying stress. The presented qualitative analysis underlines the potential of the used method of energy resolved neutron imaging for studying this phenomenon. Further investigations of anode supports at numerous different stages of reduction could hence be well suited to provide quantitative relations between reduction rate and parameters like reaction time, temperature and stress, which are crucial not only for the understanding of such processes taking place in operating SOFCs limiting their lifetimes, but subsequently also for improved sustainable material developments and designs. Such studies will be published in a separate manuscript focused on this.

\section{Conclusion}

This work presents the results of Bragg edge transmission imaging measurements of reduced, nonreduced and partly reduced anode supports of SOFCs performed at ENGIN-X (ISIS) and at CONRAD (HZB) instruments. The experiment conducted at ENGIN-X using a TOF approach has demonstrated the suitability of the method to distinguish the different phases present in the material while achieving sufficient spatial resolution to investigate gradients over the thickness of the investigated layers. The superior wavelength, i.e. energy, resolution at this TOF instrument as compared to the CONRAD instrument at a continuous source, allowed to clearly resolve corresponding Bragg edges and to identify the most distinct edges allowing for studies at the latter. Accordingly at CONRAD, providing superior spatial resolution, not only reduced and non-reduced samples, but also one anode support sample, which was stressed during reduction process, have been measured. In this only partly reduced sample the energy resolved neutron imaging measurements have, despite the limited energy 
resolution, provided clear evidence for different amounts of the reduced phase with respect to different sides of the sample. This is supporting a recent hypothesis that asymmetrical reduction rate can be caused by an asymmetric stress field in a sample, like applied during reduction of the respective anode layer (compression on one side and tension on the opposite side). The result further implies an accelerating influence of compressive stress on the reduction reaction.

Hence, this research clearly demonstrates that not only temperature and reducing atmosphere, which were considered in previous studies (Klemens $\varnothing$ et al., 2006; Li et al., 2010; Moseley et al., 2011), but also external stress during reduction of anode supports affects the reduction process significantly. Since this process determines the microstructure development and future electrochemical properties of such layers in an SOFC, which in realistic operation conditions are always exposed to stresses, understanding the correlation between external stress and reduction progress is of significant interest for the cell design and performance optimization. The presented research establishes a first proof of principle for the potential use of energy-resolved Bragg edge imaging to study mentioned processes, since the ability to detect and distinguish the $\mathrm{Ni}$ and $\mathrm{NiO}$ phases in anode supports with the required spatial resolution has been demonstrated in this work. Moreover, it is expected that due to the excellent scattering properties of $\mathrm{Ni}$, even a very short exposure time (minute(s)) can provide sufficient statistics to distinguish different phases in the investigated material. This shows a great potential of Bragg edge imaging for in situ observation of reduction progress in SOFC. Such measurements could be performed even in whole cells under operation conditions, which, to our best knowledge, is not possible with any other technique at the present time.

Acknowledgements The authors would like to acknowledge Danscatt for financial support; John Johnson, Karen Brodersen and Pernille Hedemark Nielsen for their assistance with sample preparation, Janet Bentzen for help in SEM microscopy measurements, and Steven Peetermans and Axel Steuwer for help in conducting neutron imaging experiments.

\section{References}

Allen, R., Stephenson, T., Stanford, C., \& Bernstein, S. (1954). Phys. Rev. 15, 1297-1305.

Christiansen, N., Primdahl, S., Wandel, M., Ramousse, S., \& Hagen, A. (2013). ECS Trans. 57, 4352.

Fermi, E., Sturm, W., \& Sachs, R. (1947). Phys. Rev. 71, 589-594.

Frandsen, H. L., Makowska, M., Greco, F., Ni, D. W., Curran, D. J., Strobl, M., Kuhn, L. T., \& Hendriksen, P. V. (2014). Conf. Proc. Eur. Fuel Cell Forum, Lucerne, Switz.

Ghatee, M., Shariat, M. H., \& Irvine, J. T. S. (2009). Solid State Ionics. 180, 57-62. 
Hecht, E. S., Gupta, G. K., Zhu, H., Dean, A. M., Kee, R. J., Maier, L., \& Deutschmann, O. (2005). Appl. Catal. A Gen. 295, 40-51.

Iwase, K., Sakuma, K., Kamiyama, T., \& Kiyanagi, Y. (2009). Nucl. Instruments Methods Phys. Res. Sect. A Accel. Spectrometers, Detect. Assoc. Equip. 605, 1-4.

Josic, L., Lehmann, E., \& Kaestner, a. (2011). Nucl. Instruments Methods Phys. Res. Sect. A Accel. Spectrometers, Detect. Assoc. Equip. 651, 166-170.

Kardjilov, N., Hilger, a., Manke, I., Strobl, M., Dawson, M., Williams, S., \& Banhart, J. (2011). Nucl. Instruments Methods Phys. Res. Sect. A Accel. Spectrometers, Detect. Assoc. Equip. 651, 47-52.

Kardjilov, N., Manke, I., Hilger, A., Williams, S., Strobl, M., Woracek, R., Boin, M., Lehmann, E., Penumadu, D., \& Banhart, J. (2012). Int. J. Mater. Res. (formerly Zeitschrift Fuer Met. 103, 151-154.

Klemensø, T., Appel, C. C., Mogensen, M., Lett, E. S., \& A-a, P. (2006). 9, 403-407.

Lehmann, E. H., Kaestner, a., Josic, L., Hartmann, S., \& Mannes, D. (2011). Nucl. Instruments Methods Phys. Res. Sect. A Accel. Spectrometers, Detect. Assoc. Equip. 651, 161-165.

Li, T. S., Wang, W. G., Miao, H., Chen, T., \& Xu, C. (2010). J. Alloys Compd. 495, 138-143.

Malzbender, J., Steinbrech, R. W., \& Singheiser, L. (2009). Fuel Cells. 9, 785-793.

Malzbender, J., Wessel, E., \& Steinbrech, R. (2005). Solid State Ionics. 176, 2201-2203.

Moseley, P. T., Hauch, A., Jørgensen, P. S., Brodersen, K., \& Mogensen, M. (2011). J. Power Sources. 196, 8931-8941.

Patel, S., Jawlik, P. F., Wang, L., Jackson, G. S., \& Almansoori, A. (2012). J. Fuel Cell Sci. Technol. 9, 041002.

Ramousse, S., Menon, M., Brodersen, K., Knudsen, J., Rahbek, U., \& Larsen, P. H. (2007). ECS Transactions, pp. 317-327. ECS.

Santisteban, J. R., Edwards, L., Fizpatrick, M. E., Steuwer, A., \& Withers, P. J. (2002). 1436, 1433 1436.

Santisteban, J. R., Edwards, L., Steuwer, a., \& Withers, P. J. (2001). J. Appl. Crystallogr. 34, 289297.

Singhal, S. (2000). Solid State Ionics. 135, 305-313.

Stambouli, A. B. \& Traversa, E. (2002). Renew. Sustain. Energy Rev. 6, 433-455.

Strobl, M. (2009). Nucl. Instruments Methods Phys. Res. Sect. A Accel. Spectrometers, Detect. Assoc. Equip. 604, 646-652.

Strobl, M., Hilger, A., Boin, M., Kardjilov, N., Wimpory, R., Clemens, D., Mühlbauer, M., Schillinger, B., Wilpert, T., Schulz, C., et al. (2011). Nucl. Instruments Methods Phys. Res. Sect. A Accel. Spectrometers, Detect. Assoc. Equip. 651, 149-155. 
Strobl, M., Woracek, R., Kardjilov, N., Hilger, A., Wimpory, R., Tremsin, A., Wilpert, T., Schulz, C., Manke, I., \& Penumadu, D. (2012). Nucl. Instruments Methods Phys. Res. Sect. A Accel.

Spectrometers, Detect. Assoc. Equip. 680, 27-34.

Sun, B., Rudkin, R. A., \& Atkinson, A. (2009). Fuel Cells. 9, 805-813.

Treimer, W., Strobl, M., Kardjilov, N., Hilger, A., \& Manke, I. (2006). Appl. Phys. Lett. 89, 203504.

Tremsin, A. S., McPhate, J. B., Steuwer, A., Kockelmann, W., M Paradowska, A., Kelleher, J. F., Vallerga, J. V., Siegmund, O. H. W., \& Feller, W. B. (2012a). Strain. 48, 296-305.

Tremsin, A. S., McPhate, J. B., Vallerga, J. V., Siegmund, O. H. W., Bruce Feller, W., Lehmann, E., Kaestner, A., Boillat, P., Panzner, T., \& Filges, U. (2012b). Nucl. Instruments Methods Phys. Res. Sect. A Accel. Spectrometers, Detect. Assoc. Equip. 688, 32-40.

Tremsin, A. S., Vallerga, J. V, McPhate, J. B., \& Siegmund, O. H. W. (2014). J. Instrum. 9, C05026C05026.

Tremsin, A. S., Vallerga, J. V., McPhate, J. B., Siegmund, O. H. W., \& Raffanti, R. (2013). IEEE Trans. Nucl. Sci. 60, 578-585.

Vogel, S. (2000). A Rietveld-Approach for the Analysis of Neutron Time-Of-Flight Transmission Data. Christian Albrechts Universitaet.

Vogel, S., Ustundag, E., Hanan, J. ., Yuan, V. ., \& Bourke, M. a. . (2002). Mater. Sci. Eng. A. 333, 1 9.

Wang, Y., Walter, M., Sabolsky, K., \& Seabaugh, M. (2006). Solid State Ionics. 177, 1517-1527.

Williams, S. H., Hilger, a, Kardjilov, N., Manke, I., Strobl, M., Douissard, P. a, Martin, T., Riesemeier, H., \& Banhart, J. (2012). J. Instrum. 7, P02014-P02014.

Woracek, R., Penumadu, D., Kardjilov, N., Hilger, a., Strobl, M., Wimpory, R. C., Manke, I., \& Banhart, J. (2011). J. Appl. Phys. 109, 093506.

Woracek, R., Penumadu, D., Kardjilov, N., Hilger, A., Boin, M., Banhart, J., \& Manke, I. (2014). Adv. Mater. 26, 4069-4073.

Zhang, S. Y., Evans, A., Eren, E., Chen, B., Pavier, M., Wang, Y., Pierret, S., Moat, R., \& Mori, B. (2013). Neutron News. 24, 22-26.

Table 1 Samples prepared for neutron imaging measurements.

\begin{tabular}{lllll}
\hline $\begin{array}{l}\text { Sample } \\
\text { name }\end{array}$ & Thickness along beam & reduction temperature & External & Remarks \\
& direction $(\mathrm{mm})$ & $\left({ }^{\circ} \mathrm{C}\right)$, time $(\mathrm{h})$ & stress &
\end{tabular}




\begin{tabular}{lllll}
\hline A & 6.1 & Non-reduced sample & No & \\
\hline B & 7.7 & $800^{\circ} \mathrm{C}, 1 \mathrm{~h}$, & No & re-oxidation at the surface \\
\hline C & 7.9 & $\left.800^{\circ} \mathrm{C}, 1 \mathrm{~h}\right)$ & No & sample completely reduced \\
\hline D & 5.9 & $650^{\circ} \mathrm{C}, 8$ minutes & Yes & partial reduction \\
\hline
\end{tabular}

Table 2 Samples analyzed at the two different neutron imaging facilities.

\begin{tabular}{llll}
\hline $\begin{array}{l}\text { Sample } \\
\text { name }\end{array}$ & $\begin{array}{l}\text { Instrument used for sample } \\
\text { analysis }\end{array}$ & $\begin{array}{l}\text { Neutron wavelength } \\
\text { range }[\AA]\end{array}$ & Wavelength resolution \\
\hline $\mathrm{A}$ & ENGIN-X, CONRAD & $1.4-6 ; 4-4.3$ & $0.04 \%, 3 \%$ \\
\hline $\mathrm{B}$ & ENGIN-X & $1.4-6$ & $0.04 \%$ \\
\hline $\mathrm{C}$ & CONRAD & $4-4.3$ & $3 \%$ \\
\hline $\mathrm{D}$ & CONRAD & $4-4.3$ & $3 \%$ \\
\hline
\end{tabular}

Figure 1 a) Drawing of the fixture with a sample (green element); view of the sample and part of the fixture b) - before and c) - during the reduction process observed with the camera; displacement of the load is a consequence of the sample bending because of accelerated creep.

Figure $2300 \mu \mathrm{m}$ thick NiO-3YSZ anode supports $(15 \mathrm{~mm}$ x $60 \mathrm{~mm})$ a) before reduction and b) after simultaneous exposure to reducing atmosphere and external stress.

Figure 3 Scanning electron micrographs of cross sections of the sample B acquired by the BSE detector; $\mathrm{a}-$ near the surface and $\mathrm{b}-$ in the center of the sample.

Figure 4 Macroscopic cross-section measured at ISIS ENGIN-X for YSZ-based anode supports at different phase transition stages (sample A (green line) and sample B (red line)).

Figure 5 Macroscopic cross-section obtained for different areas of sample B: in the center of the sample (red line) and close to the surface (green line).

Figure 6 Macroscopic cross sections measured at CONRAD for three different parts (compressed side - red line, center - blue line, tensioned side - green line) of anode supports in different states: a) sample A; b) sample C; c) sample D (tab. 1). At figure a) a sketch of a bended sample is included, showing the slices used for calculation of the Bragg edges.

Figure 7 First derivative of the macroscopic cross sections of two different parts of sample D (red lines): a) compressed side, b) tensioned side, both plotted together with reference curves: for nonreduced sample A (green line) and reduced sample C (blue line). 